\title{
The manpower requirements approach: background and methodology
}

Citation for published version (APA):

van Eijs, P. W. L. J. (1993). The manpower requirements approach: background and methodology.

Researchcentrum voor Onderwijs en Arbeidsmarkt, Faculteit der Economische Wetenschappen. ROA Research Memoranda No. 3E https://doi.org/10.26481/umaror.199303E

Document status and date:

Published: 01/01/1993

DOI:

10.26481/umaror.199303E

Document Version:

Publisher's PDF, also known as Version of record

\section{Please check the document version of this publication:}

- A submitted manuscript is the version of the article upon submission and before peer-review. There can be important differences between the submitted version and the official published version of record.

People interested in the research are advised to contact the author for the final version of the publication, or visit the DOI to the publisher's website.

- The final author version and the galley proof are versions of the publication after peer review.

- The final published version features the final layout of the paper including the volume, issue and page numbers.

Link to publication

\footnotetext{
General rights rights.

- You may freely distribute the URL identifying the publication in the public portal. please follow below link for the End User Agreement:

www.umlib.nl/taverne-license

Take down policy

If you believe that this document breaches copyright please contact us at:

repository@maastrichtuniversity.nl

providing details and we will investigate your claim.
}

Copyright and moral rights for the publications made accessible in the public portal are retained by the authors and/or other copyright owners and it is a condition of accessing publications that users recognise and abide by the legal requirements associated with these

- Users may download and print one copy of any publication from the public portal for the purpose of private study or research.

- You may not further distribute the material or use it for any profit-making activity or commercial gain

If the publication is distributed under the terms of Article $25 \mathrm{fa}$ of the Dutch Copyright Act, indicated by the "Taverne" license above, 
THE MANPOWER REQUIREMENTS APPROACH:

BACKGROUND AND METHODOLOGY

ROA-RM-1993/3E

Patrick van Eijs

RESEARCH CENTRE FOR EDUCATION AND THE LABOUR MARKET

Faculty of Economics and Business Administration

Rijksuniversiteit Limburg

Maastricht, April 1993 
CIP-GEGEVENS KONINKLIJKE BIBLIOTHEEK, DEN HAAG

Eijs, Patrick van

The manpower requirements approach : background and methodology / Patrick van Eijs. Maastricht : Research Centre for Education and the Labour Market, Faculty of Economics and Business Administration, Rijksuniversiteit Limburg. - (ROA-RM-1993/3E)

Met lit. opg.

ISBN 90-5321-102-0 in spiraalband

Trefw.: arbeidsmarktprognoses. 


\section{CONTENTS}

1. INTRODUCTION 1

2. THE FIRST BOOM IN MANPOWER PLANNING 4

2.1. Introduction 4

2.2. The background 4

2.3. The methodology 6

3. AN EVALUATION OF THE MANPOWER REQUIREMENTS APPROACH

3.1. Introduction 10

3.2. Arguments in favour of the approach 10

3.3. Fundamental criticism 11

$\begin{array}{ll}\text { 3.4. Methodological criticism } & 14\end{array}$

3.4.1. Introduction 14

3.4.2. The assumptions $\quad 15$

3.4.3. The data 19

3.4.4. The results 20

4. METHODOLOGICAL EVOLUTION: A SURVEY 22

4.1. Introduction 22

4.2. Adjustments within the manpower requirements framework 22

4.3. Synthetic models 28

5. CONCLUSIONS 31

$\begin{array}{ll}\text { REFERENCES } & 33\end{array}$ 


\section{ABSTRACT}

The manpower requirements approach is the best-known tool in manpower planning. This paper reviews the literature on the manpower requirements approach. Attention is paid to the following aspects: (1) the background of the popularity of the approach during the 1960s, (2) the methodology, (3) the debate on the usefulness of manpower planning in general and the manpower requirements approach in particular and (4) the methodological evolution.

The paper shows that the great popularity of the approach during the 1960 s has called forth serious criticism. The advocates of the approach have replied to this criticism in four ways: (1) by refuting the criticism, (2) by changing the goal of manpower planning from planning into providing information, (3) by improving the methodology and (4) by shortening the time horizon of the forecasts. The paper concludes that the manpower requirements approach is a very useful tool in an information system for the labour market, but that there is a need for further methodological improvements.

I would like to thank Lex Borghans, Andries de Grip and Hans Heijke for their helpful comments. 


\section{INTRODUCTION}

The demand for labour has several dimensions. Not only the aggregate demand by country or economic sector is relevant; skills and the occupational structure of employment are also very important. If demand and supply do not match with regard to these dimensions, the economy could get into serious difficulties, for example the inability to satisfy the demand for certain commodities and the appearance of structural unemployment. These phenomena could also cause social problems for the individual worker. ${ }^{1}$ In a neoclassical world the price mechanism certifies the existence of a qualitative equilibrium. In the 'real' world, however, this mechanism does not work perfectly at all. So it is very important to improve the matching process. Given the heterogeneity of the market, one of the proposed measures was planning.

The manpower planning deals with forecasting the structure of labour demand with regard to the dimensions mentioned above and translating these forecasts into educational needs. This means that by educational planning, based on these needs, the matching problems mentioned above could be solved. So the magic word behind this manpower planning view is education. The educational system matches the supply of labour to the heterogeneous demand. From this point of view, the educational system plays an important role for the production process. In other words: its main task is to create the productive factor labour (human capital) demanded on the labour market. Because investments in the educational system take a long time, longterm educational planning seems, in this view, to be the only way for policy makers to optimize the alignment between the educational system and the labour market.

In the course of time, many educational planning-models have been developed. According to Blaug (1967), three basic approaches can be distinguished:

1. the manpower requirements approach;

2. the rate of return approach;

3. the social demand approach.

The manpower requirements approach consists in using a fixed coefficient production function to forecast the structure of labour demand given the production target and the productivity by type of labour. Later on these forecasts usually are translated into educational needs. The core of this approach, extensively described for the first time by Parnes (1962), is formed by the following equation:

$$
L_{k t}=\left(1 / b_{k}\right) \cdot Y_{t}
$$

where $L_{k t}$ is the demand for workers with skill $k$ in year $t, b_{k}$ is the productivity of a worker with skill $S$ and $Y_{t}$ is the output target to be achieved.

1. The consequenses of a qualitative disequilibrium are described in OECD (1971), pp. 122-126. 
The rate of return approach builds on the human capital theory. The approach consists in calculating the (private and social) internal rate of returns on investments in creating skills. Students are supposed to choose the most favourable type of schooling (in other words: to choose the highest rate of return) and the educational system has to give them the opportunities to do so. The rate of return is calculated by the following formula:

$$
\sum_{t=1}^{m} \frac{\left(C_{k}-W_{k-1}\right)_{t}}{(1+r)^{t}}=\sum_{t=m+1}^{n} \frac{\left(W_{k}-W_{k-1}\right)_{t}}{(1+r)^{t}}
$$

where $W_{k}$ and $W_{k-1}$ are the wage levels belonging to skill levels $k$ and $k-1, C_{k}$ is the cost of achieving skill level $k, r$ is the internal rate of return (the rate of return equalizing both sides of the equation), $m$ is the length of the schooling period in years and $n$ is the length of the working life measured in years. ${ }^{2}$

The manpower requirements approach and the rate of return approach represent two extreme states of the world. Blaug (1967, p. 272) summarizes this as follows:

"...the quarrel really is about the view one takes of the real world. What we have is a picture of a continuum: to the right is a neo-classical universe, characterised by substitutabilities in both the educational and the productive system; to the left is a Leontief-universe of fixed output-coefficients, characterised by extreme complementarities in both education and industry."

It is obvious that these extreme views are both very naive. So it is not surprising that there has been a lot of research to improve the basic approaches or to synthesize them.

The social demand approach tells us what happens if no action is undertaken and anybody who wants to achieve knowledge or skills gets the opportunity. In other words: this approach deals mainly with projecting the demand for schooling by the supply-side of the labour market. ${ }^{3}$ This approach has grown out of a different view on manpower planning; the main criticism is in the one-sided demand-determined view on the labour market and the educational system the two other approaches take. According to the social demand approach, there is no need for manpower planning, because the economic system will absorb the complete labour force. In other words: the supply side determines the structure of labour demand. According to this approach, attention has to be focused on educational planning to satisfy the demand for education by individuals. This issue will be discussed later on.

Today's practice in manpower planning is mainly based on the manpower requirements

2. For a more extensive description of the rate of return approach, see Psacharopoulos (1987), pp. 342-347.

3. For the difference between forecasts and projections see Blaug (1967), pp. 254-255. 
approach. ${ }^{4}$ The practical pros of this approach compared to the rate of return approach are the relatively low data requirements and the easily interpretable results. Besides, and perhaps even more important, empirical evidence shows that rigidities and mismatches occur in the labour market. This also justifies the attention paid to manpower planning and the use of the manpower requirements method in particular. In accordance with this issue, it is important to mention that the rate of return approach has to cope with a paradox. The assumptions on which the rate of return approach is based, imply a perfect market. However, in a perfect market there is no need for planning. It is already mentioned that the social demand approach mainly focuses on educational planning.

The role of making manpower requirement forecasts now has changed compared to the past described above. The main function now is informing the supply of labour instead of being a basis for educational planning. So the aim is to diminish the rigidities (in Blaug's words: the aim is to move towards the right side of the continuum) by making the labour market more transparent. Especially the Bureau of Labor Statistics (BLS) of the US Department of Labor has played an important role in changing the objectives of manpower planning. ${ }^{5}$

The aim of this paper is to give an overview of some important aspects of manpower planning in general and the manpower requirements approach in particular. It goes into the background and the methodological evolution. Special attention is given to the debate concerning the relevance of making manpower forecasts in trying to obtain a better match between the educational system and the labour market and the views on the importance of these forecasts for policy makers. It should be stressed here that this paper only deals with the manpower requirements framework itself; it does not pretend to place the framework in the context of labour economics as a whole.

The structure of the remainder of this paper is as follows. First, section 2 describes the first stage of research in the beginning of the 1960s. This research resulted in the so called Mediterranean Regional Project of the OECD. Attention will be paid to the background of the rise of manpower planning in general and the manpower requirements approach in particular and to the methodology. In section 3 an evaluation is made. It discusses the advantages and the fundamental and methodological objections which have been made to the manpower requirements approach. It also discusses the reply to these objections. In section 4 a review is given on the methodological research, partially based on the objections, resulting in improvements of the first models. Finally in section 5 some concluding remarks will be made.

4. See Hughes (1991), p. 16. ROA, for example, uses a model which is based on this approach (See for example Dekker, De Grip and Heijke (1990)).

5. Research done by ROA is inspired by the work done by BLS. 
$-4-$

\section{THE FIRST BOOM IN MANPOWER PLANNING}

\subsection{Introduction}

Since World War II there has been an increasing interest in making forecasts about the occupational structure. In the 1950s the Bureau for Labor Statistics (BLS) developed the manpower requirements method, described briefly above, to satisfy this interest. In the 1960s manpower planning in general and the manpower requirements method in particular became very popular, mainly because they were adapted by the OECD for use in educational planning. The OECD initiated two programmes during those years: the famous Mediterranean Regional Project (MRP) and later on the Educational Investment and Planning Programme (EIP), which was similar in many respects to the MRP, but for other, more advanced, countries. Both programmes used the methodology developed by Parnes (1962), which was based on the manpower requirements method.

This section deals with two topics related to this first boom in manpower planning. First the background of this boom is discussed. In other words: the reasons for the popularity of educational planning and for the use of the manpower requirements method by the planners are described. Secondly Parnes's methodology is described, because it can be considered as the first more or less complete manpower requirements model.

\subsection{The background}

Educational planning was very much in the spotlight during the 1960s. Several reasons can be given for this phenomenon.

First, there was a sweeping change in the view on the role of education in society. Education was no longer seen merely as a means to give an individual the full scope to develop his or her talents. It was also seen as an 'industry' creating skilled manpower and contributing to the wealth of an economy. Parnes (1962, p. 7) states this as follows:

"...the growing realisation that education and training are every bit as important in contributing to productive capacity as raw manpower and physical capital. Several studies have shown that increases in labour and the stock of capital leave a substantial portion of economic growth unaccounted for, thus giving rise to the concept of the 'third factor of production', in which education is presumed to be a significant element."

Combined with the notion that it is possible to calculate the optimal amount of education for achieving a specified growth target, this changed view brought educational planning and policy to political and academic notice.

In the second place, during the post-war period economies changed rapidly. The high growth 
rates involved new technologies. These developments focused attention on preparing the labour force to cope with these rapid changes by adjusting the skill structure of the labour supply. Policy makers believed that it became necessary to make educational plans in order to anticipate future technological developments and to maintain the high growth rates. This argument was even stronger for less developed countries, for example the countries participating in the Mediterranean Regional Project. ${ }^{6}$ Their economies and educational systems were not able to cope even with current developments. Furthermore these countries wanted to achieve higher degrees of industrialisation and they saw educational planning as an important instrument to realise this goal (see OECD, 1965).

Thirdly, the fact that spending on education grew faster than national income gave rise to the fear that the educational system could get out of control. The OECD $(1965$, p. 23) considered the function of educational planning as follows:

"...to relate educational output to economic objectives and to broadly guide the consequential expansion of educational resources."

This statement can be regarded as a combination of the second and the third argument mentioned here.

Although educational planning was supposed to play an important role in any economy, special attention was paid to countries using planning on a large scale, for example by making general development plans. The importance of a good alignment between the educational plan and the overall development plan was emphasized. Furthermore the importance of alignment was linked to the importance of centralisation (see OECD, 1965).

A fourth argument in favour of educational planning was given by the notion that the labour market was not able to adjust adequately to their changing environment. This inflexibility led to persistent surpluses and shortages at the same time in the (heterogeneous) labour market. Planning was considered to be the most appropriate way to close the gaps between the supply of and the demand for labour. Because of the supposed strong link between the labour market and the educational system described above, educational planning was considered to play an important role in the reallocation in the labour market (see Ahamad and Blaug, 1973).

As mentioned above, the OECD chose the manpower requirements or fixed coefficient method to make manpower requirements forecasts. Several reasons can be given for this choice.

In the first place the method fits perfectly with the planning concept, in which a goal or target is set. In this case it is an economic goal: a production target. Furthermore the alignment between the general development plan and the educational plan is assured automatically, because the production target originated from the general development plan.

6. Greece, Italy, Portugal, Spain, Turkey and Yugoslavia. 
Secondly a, from a theoretical point of view, more attractive production function (for example a Cobb-Douglas function) cannot be used, because in such a case it is not possible to estimate the production before the employment is estimated. This implies that employment is planned now instead of forecasted. A fixed-coefficient production function is the only functional form in which production can be estimated before employment is estimated (see Tinbergen, 1965).

In the third place the commonly used decision-making method in the public sector, the costbenefit analysis, cannot be used for educational decision-making, because quantifying the benefits of educations is very difficult. The manpower requirements approach was regarded as a usable alternative (see Hollister, 1967).

Finally and most important, this method is conformable to the view of the OECD on the labour market. Two assumed features of the labour market are relevant in this context. First, already mentioned, the inflexibility. The mechanisms that could assure the matching between demand and supply on the market segments, for example wage adjustments or mobility (in a broad sense), work insufficiently. In the second place it was assumed that the substitution possibilities between the types of labour (skills) were small and that the demand for labour does not react on price-signals. Technological developments are considered to be the most important determinant of the occupational structure of the demand for labour. These two features imply that the supply of labour does not affect labour demand: the wage does not influence the productivity, the market mechanism does not work and downward displacement cannot occur. These features can also be found in the Leontief fixed coefficient production function, which is the core of the manpower requirements approach.

\subsection{The methodology}

As mentioned in section 1, the methodology was extensively described for the first time by Parnes. His paper was the starting point for the Mediterranean Regional Project. ${ }^{7}$ He described a framework that could be used for any application in this context. This means that any time the method is used the framework has to be filled in in a way tailored to the application. For example the availability of data or the special features of the sector or country have to be taken into account in this context.

According to Parnes (1962, p. 21), the aim of the manpower requirements method is:

"...forecasting manpower requirements and supplies as a basis for ascertaining the required expansion in the various levels and branches of the educational system."

He distinguishes eight steps which have to be taken to realise this goal. Briefly described these steps imply the following:

1. describe the occupational and educational structure in the base year;

7. Parnes (1962). This subsection is mainly based on chapter II-IV of this volume. 
2. forecast the size of the total labour force in the target year;

3. estimate the employment by sector in the target year;

4. forecast the occupational structure by sector and subsequently for the economy as a whole;

5. translate these forecasted occupational needs into educational needs;

6. estimate the supply of labour by educational qualifications in the target year if the educational system would not be changed;

7. compare the results of the last two steps and compute the change in size and structure of the output of the educational system to bring them in order with the results of (5);

8. calculate the enrolments necessary to achieve the results of (7).

In the remaining of this subsection these steps will be discussed in more detail.

The first step consists in describing the current manpower structure. Data about participation rates, unemployment by occupational category and the occupational structure and the educational structure of both the demand and the supply-side of the labour market have to be collected. Perhaps the most important part of this step is the development or the choice of an existing classification system with regard to economic sectors and occupations. The aim of these classification systems is to divide the labour market and the educational market into homogeneous parts. ${ }^{8}$

Secondly the total size of the supply of labour in the target year has to be estimated. A projection can be based on past trends and on changes in the socio-economic environment. This projection will act as a upper boundary on total manpower requirements; total requirements can never exceed total supply.

The third step is the first crucial one in the manpower requirements framework. It deals with estimating total employment by economic sector. Given a forecast for total demand for products and services, the demand by sector can be computed by input-output analysis. Estimates of labour productivity by sector are used to translate this demand into the amount of labour needed. Here the fixed coefficient production function is used for the first time; there are no substitution possibilities between labour and the other production factors. Because the data requirements for an input-output analysis often cannot be fulfilled, Parnes mentions some alternative methods. A first alternative consists in extrapolating past employment trends. The second alternative is very well-known and uses projections (or planned targets) of output levels and average labour productivity by sector. Parnes emphasizes in this context the difficulties that occur when productivity trends are estimated, because the factors underlying these trends are not fully known.

The fourth step deals with forecasting the occupational structure. First this is done by sector. There are several ways to make these forecasts. It is possible to use past trends, inter-firm comparisons or international comparisons. Inter-firm comparisons are based on the idea that

8. However, the availability of data could be a restrictive factor. 
firms strive for expansion. If inter-firm comparisons are used, it is implicitly assumed that the occupational structure is related to the size of the plant by assuming that this size is related to the technological level and hence to the productivity level. International comparisons are based on the idea that less developed countries want to follow the same development path as is followed by develop countries. If international comparisons are used, it is implicitly assumed that the occupational structure is related to the productivity level, which is an indication of the general level of development. Subsequently the occupational structures by sector are put together to obtain the occupational structure for the economy as a whole.

Textbooks and reviews on manpower planning describe the manpower requirements method mostly by means of formula (1) (section 1) or a variant of it. ${ }^{9}$ In fact this formula summarizes step (3) and (4). It describes how production targets are used to forecast the occupational structure. This formula also makes clear that a Leontief-technology has to be assumed to link output and manpower requirements. It is mentioned above that this assumption fits nicely with the view of the OECD on the labour market.

In the fifth step the occupational structure is translated into educational requirements. This is difficult because there is no clear and fixed relationship between an occupation on the one hand and the educational qualifications required for that occupation on the other. Parnes mentions several reasons for this lacking relationship: the broadness of the occupational categories, the complexity of jobs and differences in opinion about the relative importance of education, on-thejob training and work experience. So assumptions have to be made about the composition of the required educational background of jobs in an occupational category.

There are several ways to make these assumptions. For example, the current background of the working part of the labour force can for be used as a frame of reference. Parnes emphasizes, however, that this method implies that the current situation is taken to be ideal, which mostly is not the case. ${ }^{10}$ Another possibility is interviewing a sample of employers and workers. Theoretically the best, but at the same time the most complex approach is Eckaus's method, which consists in making a skill classification system with regard to educational needs. It is possible now to link an occupation, which is regarded as a composition of several skills, and the educational needs for this occupation. ${ }^{11}$

The sixth step deals with projecting the composition of the labour force within occupational categories by educational qualifications. The current composition has to be adjusted to take into account the expected inflow (school-leavers, people who change their job, re-entrants) and outflow (as a result of for example death, retirement or change of job) of the occupational category. This is very difficult, because in- and outflow cannot be separated. The reason is that

9. See for example Ahamad and Blaug (1973), pp. 13-16 or Psacharopoulos (1987), pp. 331-335.

10. Parnes mentions structural unemployment and downward displacement.

11. See for further details Parnes (1962), p. 39. 
the size of in- and outflow as a result of a job-change depend on the requirements, since ex post demand must match ex post supply. A less complex alternative is to project the composition of the labour force as a whole by educational qualifications.

In the last two steps the results of the forecasted requirements and the projected supply are compared. The differences between requirements and supply are used to make an educational plan. The required outputs of the educational sectors, needed to ensure that the estimated differences between requirements and supply will not occur, are computed. The last step consists in calculating the required enrolments into the educational system needed to realize the output. This results into an overview of the required enrolments by year and by educational level. This overview is used to plan the investments in the educational sector, for example the investments in school-buildings, teachers, etc..

Finally it should be mentioned here that Parnes's methodology in principle is a combination of two approaches. Parnes calls them the economic (or technological) approach and the cultural approach. The economic approach is described above. The cultural approach is in fact a qualitative predecessor of the social demand approach. Parnes considers the two approaches to be complementary. The results of the two studies have to be synthesized in order to draw up an educational plan. In practice, however, the country reports of the Mediterranean Regional Project were in fact only the results of economic studies. The OECD $(1965$, p. 6) stated this as follows:

"...the MRP does not concentrate exclusively on economic criteria in estimating educational needs: it also gives a large place to the social and cultural objectives which education serves and to the demographic trends which underlie such educational needs."

But (OECD, 1965, p. 14):

"Though the MRP has by no means neglected the social and cultural objectives of education, no specific methodology has been evolved for assessing such needs."

So (OECD, 1965, p. 15):

"The purpose of the national reports was to survey the present position and point to the deficiencies of the present system in the light of economic needs, to assess to future requirements for education and to recommend ways and means by which these requirements could be met."

The great popularity during the 1960 s resulted in a debate about the relevance and the usefulness of the manpower requirements approach. The next section describes this debate. Attention will be paid to the arguments in favour of the approach and to the criticism that the great popularity has called forth. 


\section{AN EVALUATION OF THE MANPOWER REQUIREMENTS APPROACH}

\subsection{Introduction}

Immediately after the first stage of the Mediterranean Regional Project was rounded off, a sprightly debate on educational planning in general and the manpower requirements approach in particular arose. This debate has continued until now. This section evaluates the manpower requirement approach by describing the debate.

First, section 3.2 describes the arguments in favour of educational planning and the manpower requirements approach. However, the approach has also called forth considerable criticism. Two kinds of criticism are distinguished, although it will be clear that drawing a strict dividing line is very difficult. Criticism with regard to making manpower forecasts using the manpower requirements approach and using these forecasts for educational planning may be called fundamental criticism and is described in section 3.3. Criticism with regard to techniques of the manpower requirements approach may be called methodological criticism and is described in section 3.4. Of course also attention will be paid to the advocates' reply to this criticism.

\subsection{Arguments in favour of the approach}

The arguments of the advocates of educational planning in general have been described in section 2.2. Briefly summarized these arguments in favour of educational planning are:

1. education is the "third factor in production", so shortages may have a considerable impact on wealth;

2. the economies change rapidly, which means that the labour force has to be prepared adequately to cope with these quick developments;

3. the educational system grows very fast and could get out of control;

4. the labour market is very inflexible, so planning is the only way to avoid the occurrence of skill shortages.

The arguments in favour of the manpower requirements approach in particular have also been partly described in section 2.2. In this section, the following arguments are mentioned:

1. the perfect alignment with the concept of planning; the output is fixed first and the implication for the labour demand are computed afterwards;

2. the possibility to estimate the production before the employment, which is only possible when a fixed-coefficient function is used;

3. the ability to replace the cost-benefit analysis in decision-making, which is desirable because the benefits of an educational plan are very difficult to compute;

4. the alignment with the view on the labour market; in particular the inflexibility of this market and the lacking substitution-possibilities. These features return in the fixed-coefficient production-function.

Later on, the following arguments are added (Psacharopoulos, 1987a):

5. the intuitive attractiveness. The approach yields point-estimates and does not use difficult 
mathematics;

6. the low data requirements compared to other approaches, especially the rate-of-return approach.

\subsection{Fundamental criticism}

As mentioned in section 2.1, manpower planning techniques in general and the manpower requirements approach in particular were used for educational planning purposes on a large scale during the 1960s. The important role of manpower planning in educational planning is criticized by both the researchers on manpower planning and other educational scientists. These criticisms involve several arguments with regard to: the weakness of the techniques, the impact of manpower forecasts on the working of the educational system, two paradoxes in manpower planning (the long-run paradox and the rigidity paradox) and the size of the required changes in the educational system. These arguments are described in this section. Finally some attention will be paid to the change in the role of manpower planning, which can be viewed as a reply on these criticisms.

It is proposed, for example by Hollister (1967), that serious doubts can be made about the impact of manpower requirements on the educational system. Two arguments are given by Hollister for this proposition:

1. the forecast techniques are so weak that the forecasts cannot be used as a useful base for educational policy;

2. manpower requirements do not influence the working of the educational system.

These two points can, under certain circumstances, be considered as two fundamental arguments against manpower planning.

Hollister, however, considers the first argument to be a methodological issue. He considers the weakness of the techniques to be a serious but solvable problem. This problem could be solved if better techniques were elaborated. ${ }^{12}$ However, Hollister is not the only one who considers the forecast techniques to be weak. If this weakness is considerable it is impossible to make exact estimates. These techniques could probably even produce wrong estimates. This could be considered as a methodological problem, that could be solved if better techniques are used. However, some critics consider these problems to be unsolvable and consider this to be a serious argument against the use of manpower planning.

The second point made by Hollister, however, is purely fundamental; if manpower requirements do not have a significant impact on developments in the educational system, the making of manpower forecasts would be of little importance.

12. Because this argument can be considered to be methodological, it will be discussed also in section 3.4. 
Hollister tries to measure the impact of manpower requirements in two ways. ${ }^{13}$ First he distinguishes three sources of educational requirements: (1) those needed to cope with the growth of the labour force, (2) those needed to cope with required adjustments in the occupational structure of the labour force and (3) those needed to cope with shifts in the educational requirements for particular occupations. The first element has nothing to do with the requirements stemming from the demand side of the labour market. So, if the first element appears to be the most important, serious doubts about the usefulness of manpower planning could be made.

Secondly Hollister does a so-called shift and share analysis. In other words: he tries to measure the impact of manpower requirements by investigating the relative importance of the second and the third element. He finds that the third element, dealing with shifts in the occupationaleducational relationships, seems to be the most important. More recent studies for the Netherlands (for example Peeters (1990) and NEI (1986)) show that shifts in the educational structure are due to shifts in the occupational structure of labour demand as well as shifts in the educational structure within occupations. However, like Hollister, these studies show that the last element seems to be most important. Hollister argues that this could also raise serious doubts about the relevance of manpower planning and that the social demand approach could be more useful then. Hollister (1967, p. 66 and 67) states that if the third element is found to be the most important:

"Such a finding could be viewed in two general ways. First the shift in the educational stock in the labour force could be largely unrelated to the production requirements of the economy. That is, most of the education could be acquired for the purposes which have often been lumped under the heading of 'social demand'.... The second general view is to consider that there is a connection between the growing, changing productive processes and the changing occupationaleducational relationships....If this were the case, then the measured impact could still be said to be due to manpower requirements."

If the first view mentioned in this quotation is valid, making forecasts is not relevant, because in that case it is supply that determines demand. In other words: the demand-side of the labour market is flexible enough to absorb the available supply. This notion underlies the social demand approach. A concrete elaboration of this approach is the absorption approach of the 'Max Planck Institut' (see Van Hoof and Dronkers, 1980). The second view, however, aligns perfectly with the manpower planning view. The demand-side of the labour market determines the occupational-educational relationships.

In the third argument against manpower planning critics emphasize the occurrence of two paradoxes in manpower planning: the long-run paradox and the rigidity paradox. Ahamad and Blaug

13. The results of these attempts are not presented here, because they are only meant as an example how to do this. 
(1973, p. 8) describe the long-run paradox as follows:

"We have the paradoxical situation that manpower forecasting should be long-term to be really useful for educational decisions but, unfortunately, highly accurate forecasting is only possible in the short-term or medium-term."

The advocates of manpower planning indeed try to get around this paradox by shortening the time horizon of their studies (see Ahamad and Blaug, 1973). The rigidity paradox is described by Blaug $(1967$, p. 276):

'...because of alleged rigidities in the educational system and imperfections in the labour market, one must forecast the demand for educated people so as to avoid structural disequilibria; but if there is indeed little synchronisation between the educational system and the labour market errors in forecasting lead to an irremediable waste of resources."

Critics claim that these paradoxes are inseparable from manpower planning. So, in their view, these paradoxes are a third fundamental argument against manpower planning.

The fourth argument links up with the second one. Ahamad and Blaug (1973) argue that the required changes in the educational structure of the labour supply are usually marginal. In that case the educational system is flexible enough to cope with a changing demand from the labour market.

The line of reasoning in the fourth argument already indicates the alternative suggested by the critics of manpower planning. In their view, more attention should be paid to making the educational system more flexible, instead of to planning a rigid market (see, for example, Blaug, 1967). If the educational system is flexible enough, manpower planning becomes superfluous. Proposed measures to reform the educational system are: avoiding early specialisation, allowing students freely to choose their type of schooling and giving them good information so they can make a good choice and finally creating incentives to firms to improve their internal schooling and on-the-job training.

Finally the purpose of making manpower forecasts has to be discussed. This purpose has changed since the fist boom in manpower planning during the 1960s. Instead of a planning instrument, the manpower planning framework is often used now as an instrument generating information for all participants on the labour market, especially the potential students (see Hughes, 1991). In this way the framework can be viewed as an instrument making the market more transparent. Borghans (1993) shows that the provision of good labour market forecasts improves both the labour market performance and the fit between the educational system and the labour market. Looking at the fundamental arguments against manpower planning mentioned here, this change in the objective of manpower planning can be considered as a reply to these arguments. Manpower planners accepted the validity of the criticisms. Ahamad and Blaug 
(1973, p. 7) were among the first who discerned that these criticisms were not the end of the manpower planning framework:

"These criticisms are sound so far as they go, but they ignore the fact that longterm forecasts may also provide valuable information for decision-making by individuals. If students choose careers only on the basis of current labour market information, they may find that the market situation has been considerably altered by the time they join the labour market."

If the manpower forecasts are considered to be a source of information, the fundamental arguments against manpower planning indeed seem to become less valid. The fact that educational choices not only depend on the demand by employers, but also on social demand, does no longer conflict with the manpower planning framework, because students are no longer 'forced' to make a particular choice. They can use the manpower forecasts as a help to make their choice. This new role also makes lower demands upon the forecasts. The direction of future developments is much more important now than the exact size of these developments. This also means that the weakness becomes more and more a methodological issue, because lower requirements can be made upon improvements of the techniques.

\subsection{Methodological criticism}

\subsubsection{Introduction}

Methodological criticism differs from fundamental criticism, because it does not stem from doubts about the relevance of manpower planning as a whole. Methodological criticism is a result of the evaluation of the techniques. In other words: there are no doubts about the usefulness of manpower planning. It is the method used to make the manpower forecasts, the manpower requirements approach, that raises serious doubts. In contrast with fundamental criticism, most of the time these doubts do not result into a complete rejection of the approach. Often these doubts are the starting-point for attempts to improve the approach. ${ }^{14}$

To put it briefly, three aspects of the manpower requirements methodology are criticised. First of all, the assumptions that are made, especially the lack of substitution possibilities between production factors and the missing supply effects, the unique occupational-educational relationships and the role of (formal) education in society. Secondly the character of the data is considered. Issues that are related to this aspect are: the degree of disaggregation and the description of occupations in educational terms. The last aspect is the quality and the usefulness of the results of the manpower planning work: these are, the forecasts. This aspect entails the sensitivity of the results with regard to uncertain forecasts of the exogenous variables and the character of the results. In the remainder of this section these aspects are discussed in more detail.

14. In section 4 these attempts will be discussed. 


\subsubsection{The assumptions}

First, attention should be paid to the criticism with regard to the assumptions underlying the manpower requirements approach. One of the most striking features of the approach is the production function, which is assumed to be of the Leontief-type. Using this production function has, as already mentioned, several important implications. First, this type of production function implies that a given production can only be produced by one specific mix of the several production factors or, in this case, several types of labour (skills). Secondly the input of a particular type of labour is not influenced by the supply of that type. In other words: the elasticity of substitution between the types of labour is zero.

This production function is one of the most criticized features of the requirements approach for two reasons: first, because the implications seem to be very unrealistic and secondly because the most important 'rival' of the requirements approach, the rate of return approach, implies unlimited substitution possibilities.

Making wrong assumptions with regard to substitution possibilities could influence the performance of the approach at two levels (see Hollister, 1967). First of all, the observed historical data could be misinterpretated. If substitution is possible, these data do not reflect only the impact of the output structure, but also the supply effects. The second level has to do with the forecasts. If substitution possibilities occur and if these possibilities are not taken into account, the forecasts could be seriously biased.

The assumed impossibility to substitute between labour skills, is the most striking feature of the manpower requirements approach. Therefore, a lot of research has been done to investigate the plausibility of this feature of the requirements approach. There are several ways to do this, for example indirectly by investigating to what extent production volumes are produced by different factor mixes or directly by trying to measure the elasticity of substitution.

The first method is used by Hollister (1967). He uses data generated within the framework of the Mediterranean Regional Project to compare occupation coefficients in similar sectors in different countries. Although his results should be treated with great care, some conclusions can be drawn. ${ }^{15}$ In the first place, the data show that there are very great differences between the occupational coefficients. Secondly, assuming that there are substitution possibilities leads to estimates which differ significantly from the original forecasts.

Several studies tried to review the attempts made to measure the substitution possibilities.

15. There are three reasons for this caution. In the first place the amount of data on which the conclusions are based, is very small. Secondly it is very difficult to compare data between countries, foe example because there are differences between the classification systems. Finally," if international comparisons are made there are a lot of factors that could cause differences in the occupational structure, for example: differences in the technological knowledge or differences in the availibility of other production factors. 
Psacharopoulos (1973) is one of these. Psacharopoulos also distinguishes the two kinds of evidence mentioned before and calls them informal and formal evidence. Informal evidence entails the indirect ways to measure substitution possibilities: comparing labour coefficients between firms, countries or different points of time. ${ }^{16}$ Formal evidence consists in attempts to measure the elasticity of substitution between types of labour directly. Psacharopoulos concludes that both informal and formal evidence seem to reject the assumptions made within the manpower requirements framework; the elasticities of substitution seem to be significantly different from zero. These findings seem to underpin the rate of return approach. He also concludes that further research should deal with the elaboration of a planning model in which intermediate values of elasticities are assumed.

Hughes (1991) also reviews the attempts very briefly. Based on this review, it seems to be possible to conclude that the elasticities of substitution are relatively low, with the exception of the elasticity of substitution between less skilled and more skilled labour. As a result it seems to be impossible to draw an unambiguous conclusion from the empirical evidence reviewed by Psacharopoulos and Hughes. In other words: based on this empirical evidence it is not possible to underpin the Leontief production function.

Because of the inconclusiveness of the empirical evidence, other ways have to be found to underpin the usefulness of the Leontief production function. Most of the empirical studies try to make a choice between the manpower requirements approach and the rate of return approach. It is mentioned in section 1 that Blaug emphasizes the complementary character of the approaches, because every submarket is characterised by a different degree of substitution possibilities. In some submarkets the Leontief production function is useful, in others it is not. In other words, according to Blaug, it is not relevant to make a choice based on empirical evidence between the approaches for the economy as a whole.

Freeman (1980) tries to underpin the fixed-coefficient production function by estimating the importance of both fixed coefficient shifts in the demand for labour and shifts due to substitution. He tests a model in which it is assumed that shifts in the demand for a specific kind of labour both can be brought on by shifts in the total demand for labour in a economic sector and by shifts in the specific labour-output ratios. The first effect indicates manpower requirement adjustments; the second effect indicates substitution. ${ }^{17}$ It is assumed that substitution is caused by shifts in the relative wages. These assumptions can be found in the following demand function:

$$
\dot{L}_{d i}=\dot{D}_{i}-\eta_{i} \dot{W}_{i}+\mu_{i}
$$

16. The research done by Hollister which is described above comes under informal evidence.

17. It should be stressed that Freeman pays no attention the shifts in the occupational-educational relationships. 
where $L_{d i}$ is the demand for labour in occupation $i, W_{i}$ is the wage level and $\mu_{i}$ is a residual term. $D_{i}$ is the shift caused by manpower requirements. The dots denote percentual changes; this means that $\eta_{\mathrm{i}}$ is the wage elasticity of the demand for labour in occupation $\mathrm{i}$ and that $\eta_{\mathrm{i}} \mathrm{W}_{\mathrm{i}}$ is the substitution effect.

On the other side is the supply of labour, that is described by the following equation:

$$
\dot{L}_{s i}=\dot{S}_{i}+\phi_{i} \dot{W}_{i}+\Sigma_{i}
$$

where $L_{s i}$ is the supply of labour in occupation $i$ and $\Sigma_{i}$ is a residual term. $S_{i}$ is an exogeneous factor. Because this equation also denotes percentual changes and $\phi_{\mathrm{i}}$ is the wage elasticity of the supply of labour in occupation $\mathrm{i}, \phi_{\mathrm{i}} \mathrm{W}_{\mathrm{i}}$ is the substitution effect.

By equalizing (3) and (4), the shift in the employment in occupation $i$ when the market is in equilibrium $\left(\mathrm{L}_{\mathrm{i}}\right)$ can be derived:

$$
\dot{L}_{i}=\frac{\left(\phi_{i} \dot{D}_{i}+\eta_{i} \dot{S}_{i}\right)}{\eta_{i}+\phi_{i}}+\frac{\left(\phi_{i} \mu_{i}+\eta_{i} \Sigma_{i}\right)}{\eta_{i}+\phi_{i}}
$$

Equation (5) shows that, on average, changes in employment depend on a weighted average of the shift in demand and the shift in supply. If it is assumed that the exogenous supply does not change, the manpower requirements model provides unbiased forecasts under two conditions:

1. the wage elasticity of labour demand is zero $(\eta=0)$. This is the common assumption made in manpower requirements models;

2. the wage elasticity of labour supply is infinitely large $(\phi=\infty)$. This condition implies that wage adjustments are very small.

In general: the manpower requirements framework can be empirically underpinned by this model if $\phi / \eta$ is large. ${ }^{18}$

The empirical research done by Freeman yields the following results:

1. changes in employment are much greater than changes in wages. Freeman gives several possible explanations for this result:

a. the demand for labour is very elastic;

b. shifts in demand and supply for labour are highly correlated;

c. the supply for labour is very elastic.

The data given by Freeman seem to underpin explanation (c);

2. L en D are highly correlated;

3. empirical testing of equation (5) shows that shifts in both the demand and the supply
18. If the exogenous supply is not constant, the condition is: 
have a significant effect on employment. The impact of demand reveals to be significantly larger than the impact of supply $(\phi>\eta)$.

Freeman concludes that the manpower requirements approach can do a good job, because L and $D$ seem to be highly correlated. However, the good performance is not brought about by the assumptions, because the elasticity of the demand for labour and thus the substitution possibilities are significantly different from zero. The good performance is brought about by the large elasticity of supply, because this yields large changes in employment and small changes in wages. So it can be concluded that Freeman does not reject the criticism that the assumed absence of substitution possibilities is not realistic. But it can also be concluded that he thinks that this is not enough to reject the approach as a whole. ${ }^{19}$

The second assumption that is often criticized is strongly related to the first one. It is not only assumed that there are no substitution possibilities on the labour market; at the same time it is assumed that substitution is not possible on the educational market (see Hollister, 1967). Being employed in a specific sector and practising a specific profession in that sector needs a specific mix of skills, which can only be acquired by one specific educational route. Although it is as important as the assumption with regard to substitution on the labour market, this assumption with regard to substitution on the educational market attained much less attention as a separately discussed topic. No empirical studies testing the truth content of this assumption can be found. Most of the time it is embedded in the discussion about the possibilities to translate the occupational structure into the educational structure. ${ }^{20}$

The assumed absence of substitution possibilities and thus of supply-effects implies that demand and supply are treated to be two completely separated elements in the manpower requirements framework. Because the manpower requirements approach concentrates on the demand-side of the labour and the educational market, Freeman (1977) asserts that the approach does not pay enough attention to the supply-side. Often only past trends are extrapolated without taking care of or making assumptions about underlying factors.

There are some other assumptions underlying the manpower requirements approach that have been exposed to criticism. These assumptions are less crucial compared to the assumptions with regard to the substitution possibilities. However, they are important enough to cause substantial biases in the forecasts if these assumptions are inconsistent with reality. Some of these assumption are discussed now.

First of all it is assumed in the manpower requirement approach that formal education is the only way to acquire skills. The possibilities to adjust the skills of the labour supply to changing needs by means of on-the-job training or employers' retraining schemes are neglected. As a result the required shifts in the educational output tend to be over-estimated (see Ahamad and

19. As mentioned, Freeman underpins this by stating that theelasticity of supply is large. Another possibilty could be the rigidity of wages.

20. This issue will be discusssed in section 3.4.3. 
Blaug, 1973).

In the second place it is assumed that there is a causal relationship between education and economic growth: the higher the level of education, the higher the level of economic growth. This means that no attention is paid to the relationship the other way around: the higher the level of economic growth, the greater the resources to improve the educational system. Especially to the international comparisons method, which relies heavily on this assumption, critical side-notes can be added (see Ahamad and Blaug, 1973).

Finally, education is assumed to be an investment; it contributes to both individual and social welfare. However, education also has a consumption effect; people like it to get education (in economic terms: they gain utility from it). If this consumption effect appears to be significant, it should be taken into account when the educational structure of the labour supply is forecasted. If it is not, the educational level of the labour supply will, on average, be under-estimated. In other words: the required investments in the educational system are over-estimated (see Cohn and Geske, 1990).

\subsubsection{The data}

The second aspect that is criticized is the input: that is, the data. The criticism entails two elements: the degree of disaggregation and the translation of the occupational into the educational structure. The first step of the manpower requirements approach consists in the description of the current occupational and educational structure. In other words, in this stage data are collected. This means, among other things, that decisions have to be made on which degree of disaggregation of the data (and of course forecasts) is chosen. The disaggregation issue occurs at three levels: (1) the division of the economy into sectors, (2) the division of the labour market into occupation segments and (3) the division of the educational market into schooling segments. Critics of the approach emphasize two problems related to this issue.

First, Ahamad and Blaug (1973) argue that this choice entails a trade-off between usefulness and accuracy that cannot be avoided. The higher the degree of disaggregation, the more useful the forecasts are. However, a price has to be paid for this usefulness: the higher the degree of disaggregation, the greater the substitution possibilities between the segments are and, hence, the less accurate the forecasts are.

Secondly, Hollister (1967) argues that the relationship between output and educational inputs are so complex that they can only be described accurately on the level of the individual firm. This extreme form of disaggregation implies very high data requirements and raises serious doubts about the usefulness of the manpower requirements approach at the macro-level.

Much more attention has been paid to the fifth step in the manpower requirements approach: the translation of the occupational into the educational structure. This stage is often considered to be the weakest link in the approach, because empirical data about the occupational- 
educational relationships are scarce and difficult to collect. Very little is known, for example, about the substitution possibilities on the educational market and between formal and informal education (see section 3.4.2), the skills needed for a particular occupation and the impact of changes in, for example, technology or educational knowledge on occupational-educational relationships. Furthermore, as mentioned in section 2.3, the elaboration of a theoretical model in which occupations are linked with educational needs (a skill classification system) has appeared to be very difficult.

This problem becomes even more important if Hollister's research on the impact of manpower requirements is taken into account. He concludes that changes in the occupational-educational relationships are the main sources for changes in educational requirements (see section 3.3). Together with the possibility that social demand factors have a greater impact than manpower requirements, this finding emphasizes the importance of the fifth step of the approach. Some critics go even further. Blaug (1967) argues that the problem is so complex that it cannot be solved satisfactory. This means that this problem can also be considered to be fundamental instead of methodological.

Users of the manpower requirements approach discerned the importance of this problem. ${ }^{21}$ Along with the elaboration of more useful theoretical models, of which the description goes beyond the scope of this paper, several solutions have been suggested. Among them are 'informal guesses', linking the fourth and the fifth step and forecasting the educational structure directly from the total employment estimate without estimating the occupational structure and, finally, the use of time series analysis to discover trends in the occupational-educational relationships (without bothering about the underlying relationships (see OECD, 1971).

\subsubsection{The results}

The third aspect subject to methodological criticism is the output of the requirements approach: the forecasts. The criticism entails two elements: the character of the results and the sensitivity with regard to uncertain forecasts of exogenous variables. First, critics mention the fact that, although in most studies it is recognized that the future is subject to a lot of uncertainties, the results often are presented as point-estimates. ${ }^{22}$ This way of presentation implies that it is suggested that the future can be predicted with perfect certainty, which is of course misleading. It also implies that little attention is paid to sensitivity analysis. Both Ahamad and Blaug (1973) and Hollister (1967) emphasize the potentialities of sensitivity analysis; the outcomes of alternative assumptions and scenarios can be compared. Furthermore, the fact that only estimates for the target-year are presented is criticized. It is stressed that this implies that 'bottlenecks', for example in the supply of teachers, cannot be discovered (see Psacharopoulos, 1987b).

21. As described in section 2.3, even Parnes (1962) paid much attention to it.

22. As mentioned in section 3.2 this feature is at the same time also considered to be one of the most attractive aspects of the approach, because point-estimates are easily interpretable. 
The fact that little attention is paid to sensitivity analysis also implies that in manpower requirements studies little care has been taken about the sensitivity of the forecasts with regard to uncertain forecasts of exogenous variables. Critics argue that the uncertainty of the future is attended by substantially biased forecasts of the exogenous variables. Along with the questionable model specification, both the fact that biased estimates of the exogenous variables are likely to occur and the sensitivity with regard to these estimates make the forecasts unreliable. In this context, especially the difficulties that occur if productivity levels and (sectoral) outputs are estimated and the influence of these difficulties on the quality accuracy of the estimates, are important. Hollister $(1967$, p. 56) states this as follows:

"...assumptions concerning the GDP and productivity growth rates in each sector have been to a large extent the determining factors in the formulation of the projected occupational estimates. A more forceful way of stating this conclusion is that a small error in the estimate of either the growth rate or the productivity change would entirely wipe out the effectiveness of extremely careful and accurate estimates of shifts in the occupational distribution within a sector or of the relative growth of various economic sectors."

Finally two points related to this last issue should be mentioned. First, there is the danger of estimating the exogenous variables, especially the productivity levels, by means of extrapolation techniques. This issue is mentioned in the previous section. The problem is that historical data, for example of the occupational structure by sector, do not reflect requirements only. They also incorporate supply effects, because ex post gaps between requirements and supply have to disappear.

In the second place the implicitly assumed independency of occupational structure, productivity and output seems to be unrealistic (see Ahamad and Blaug, 1973). For example, a positive relationship between output and productivity seems, within bounds, to be likely to occur: the higher the output level, the higher labour productivity due to economies of scale or learning effects. Furthermore another output level could imply another production technique and hence another occupational structure.

In this section, the criticism on manpower planning in general and the manpower requirements approach in particular is reviewed. Attention has also been paid to the advocates' reply to these criticisms. They were able to refute part of the criticism. Furthermore, they have shortened the time horizon of planning and they have changed the purpose of making manpower forecasts. However, one type of reply has not been mentioned: theoretical adjustments in the methodology used. This issue will be the topic of the next section. 


\section{METHODOLOGICAL EVOLUTION: A SURVEY ${ }^{23}$}

\subsection{Introduction}

Since the first boom in manpower planning and the introduction of Parnes's methodology, time has not stood still. A lot of research has been done in order to improve the manpower requirements methodology and to meet the criticism described in section 3 . This section reviews some of the most important developments. Two types of improvements are distinguished. In the first place attention is paid to adjustments within the manpower requirements framework. Section 4.2 discusses these attempts to improve the manpower requirements models. Especially the various ways to incorporate supply effects and substitution possibilities into the framework attracted a lot of attention in this context. Section 4.3 deals with a particular way to introduce supply effects and substitution possibilities: syntheses between the main approaches mentioned in section 1, particularly the syntheses between the manpower requirements approach and the rate of return approach.

\subsection{Adjustments within the manpower requirements framework}

In consequence of the great popularity of manpower planning during the 1960s, a lot of research was done to improve Parnes's methodology. Tinbergen and Bos (1965) were among the first who brought about a substantial improvement. They have developed an input-output planning model in which not only the occupational and educational structure in the target year is determined, but also the path along which this structure can be realized during the intermediate years. Four characteristics of the relationship between the economic and the educational system make up the starting-point of their model:

1. economic life needs a stock of manpower;

2. education often consists of a series of successive stages;

3. part of the stock of qualified manpower must be used in the education process;

4. qualified manpower may be imported.

Especially the second and the third characteristic imply that the intermediate years between the base and the target year have to be taken into account.

The basic model can be described as follows. Three educational levels are distinguished. The primary level is no bottleneck and therefore it does not play a role in the model. The labour force with secondary education is used for production only and the third-level labour force is used for both education and production. In alignment with the manpower requirements approach, a fixed coefficient production function is used to link the second and third-level labour force with production. Linear relationships are used to determine the labour force by educational level. These relationships take inflows (from the educational system) and outflows (due to death or retirement) into account. Finally a fixed coefficient 'production function' is introduced to

23. This section does not pretend to give an exhaustive overview. It only tries to give some important examples of ways to improve the manpower requirements model. 
calculate the required number of teachers (taken from the third-level labour force) based on the number of secondary and third-level students.

The basic ideas can be found in a highly simplified dynamic linear model. It is an important improvement compared with Parnes's method, because this model can be used to trace bottlenecks in both the educational system (shortage of teachers) and the production sector (shortages of educated people) during the intermediate years. In other words: an explanation is given for the shortages and surpluses that occur in the target year. This extra information is an important tool for educational policy.

Tinbergen and Bos consider several generalizations of the basic model. Two of these are important in the scope of this paper:

1. a non-linear labour demand function can be incorporated into the model. This does not necessarily imply that substitution possibilities are introduced, but that the coefficients in the production function are for example related to per capita income;

2. a sectoral disaggregation of production can be used. This of course does not change the fundamental character of the model. ${ }^{24}$

The model of Tinbergen and Bos can be considered to be a reply to the criticism that the manpower requirements method does concentrate on the target year only. This model is an exception however. Far the most studies concentrate on introducing substitution possibilities and supply effects into the manpower requirements framework.

One of the most obvious ways to introduce substitution possibilities and supply effects is replacing the Leontief production function by a function that implies substitution possibilities, for example a Cobb-Douglas or a CES-function. Den Hartog and Thoolen (1971) have pursued this possibility. They introduce a Cobb-Douglas production function with two production factors: labour and capital. This production function implies, however, that there are no substitution possibilities between the various types of labour. Den Hartog and Thoolen did not incorporate these types into the production function, because did not have the adequate data. Therefore, they use some exogenous variables to explain trends in the input coefficients. This model will be discussed later on in this section.

An alternative is given by Freeman $(1977,1980)$. He introduces substitution possibilities and supply effects by integrating supply and demand in one model instead of forecasting demand and supply separately and confronting them afterwards. Freeman's model has already been described in section 3.4.2. Of course, this model is not only useful for testing the validity of the manpower requirement approach, but also for forecasting the occupational or educational structure. However, this application can be useful only, if forecasts of the future wage structure

24. Other possibilities to generalize the model are: alternative treatments of retirement, incorporating the possibility that students leave school without completing their studies, increasing the number of educational levels, using smaller time units, etc. However, these extensions do not change the character of the model. 
are available. It is useful to repeat here that the core of this model is made up by the following equations:

$$
\begin{aligned}
& \dot{L}_{d i}=\dot{D}_{i}-\eta_{i} \dot{W}_{i}+\mu_{i} \\
& \dot{L}_{s i}=\dot{S}_{i}+\phi_{i} \dot{W}_{i}+\Sigma_{i}
\end{aligned}
$$

In fact, Freeman uses a production function characterised by non-zero substitution elasticities implicitly, because only from such a production function (Hicksian) demand functions in which the demand for labour depends on the wage level can be derived.

The idea behind this model can also be summarized in a figure:

figure 1: graphic synthesis of manpower requirements and substitution analysis of demand ${ }^{25}$

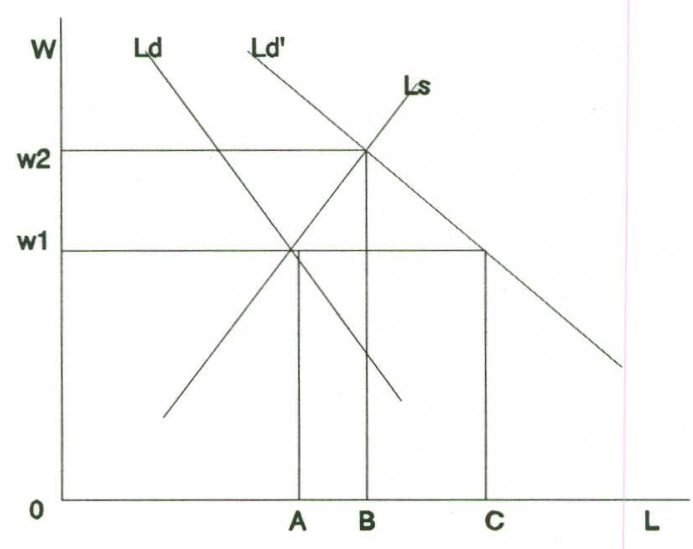

Figure 1 shows that the manpower requirements model without substitution possibilities in fact forecasts the size of the horizontal shifts in demand $L_{d}(A C)$. This is a perfect forecast of the shift in employment $L$ if no shifts in supply $L_{s}$ occur and one of the following conditions holds:

1. the elasticity of demand is zero, which is the assumption underlying the manpower requirements approach;

2. the elasticity of supply is infinite.

If neither condition (1), nor condition (2) holds, Freeman's model, which also takes account of the substitution effect (a movement along the demand curve) in consequence of the wage shift from w1 to w2 (BC), does a better job.

Den Hartog and Thoolen and Freeman use theoretical tools to cope with substitution effects. The so-called RAS method, which is introduced in manpower planning by Evans and Lindley (1973) is a mathematical tool. Starting point of the RAS-method is today's sector-skill matrix $A^{t} . A_{i j}$ is the number of workers with skill $i$ employed in sector $j$. The RAS-method tries to incor-

25. This figure is taken from Freeman (1977), p. 162. 
porate two kinds of substitution: capital-labour substitution and skill substitution. Capital-labour substitution is incorporated by adjusting every cell in column $j$ of the matrix $A^{t}$ for changes in the total employment in sector $\mathrm{j}$ (adjusting for the sector constraint):

$$
\left(A_{i j}^{t+1}\right)^{1}=A_{i j}^{t} \cdot \frac{v_{j}^{t+1}}{v_{j}^{t}}
$$

where $\left(A^{t+1}\right)^{1}$ denotes the first forecast of $A^{t+1}$ and $v_{j}$ is total employment in sector $j .{ }^{26}$

Then, skill substitution is incorporated by adjusting every cell in row $i$ of the matrix $\left.A^{t+1}\right)^{1}$ for changes in the total employment in skill $\mathrm{i}$ (adjusting for the skill constraint):

$$
\left(A_{i j}^{t+1}\right)^{2}=\frac{u_{i}^{t+1}}{\sum_{j=1}^{J}\left(A_{i j}^{t+1}\right)^{1}} \cdot\left(A_{i j}^{t+1}\right)^{1}
$$

where $u_{i}$ is total employment in skill $i$ and $\left(A^{t+1}\right)^{2}$ denotes the second forecast of $A^{t+1}$.

The RAS method uses both adjustments in turn in an iterative process in order to forecast the future matrix $A^{t+1}$ from the matrix $A^{t}$. So in the third step the matrix is adjusted for total sectoral employment again. This implies that after the adjustment for sectoral employment the skill constraint is violated and that after the adjustment for employment by skill the sector constraint is violated. However, the more iterations are executed, the smaller these violations are. In other words, the forecasts converge to a particular matrix $A^{t+1}$ which satisfies both constraints.

Evans and Lindley also try to give an economic foundation for the use of the RAS method in manpower forecasting. It can be shown that the RAS method minimizes the 'distance' between the matrices $A^{t}$ and $A^{t+1}$. Evans and Lindley suggest that this mathematical characteristic can be explained economically in a reasonable way by suggesting that the labour market tries to minimise the shifts in labour force composition. An economic interpretation of the mathematics of the RAS-method is that on the one hand the supply and demand together determine the composition of labour supply, while on the other hand firms make a choice with regard to total employment. However, the composition by skills of the employees is determined by the labour market. In other words, a major drawback of the RAS-method is that a foundation for the allocation of skills among industries and firms is not given.

26. By using this equation, it is assumed implicitly that the substitution possibilities between labour and capital are the same for all skills. Studies have shown that the validity of this assumption is questionable. Ritzen (1985), for example has found that low-skilled labour is complemaentary with capital whereas high-skilled labour is substitutable. 
Cohen (1988) also uses the RAS model. He forecasts the occupational and the educational structure of the demand for and the supply of labour by using very simple fixed coefficient equations. The RAS method is used to obtain a foundation for the determination of the fixed coefficients. If occupational and educational imbalances (shortages or surpluses) occur these coefficients have to be adjusted to close the gaps. In other words, supply effects occur. According to Cohen, this adjustment process can be described as a trial and error search by suppliers and demanders. Here the RAS model comes into the picture: the trial and error process can be simulated by the iterative RAS process. The occupational structure is determined by the demanders whereas the educational structure is determined by the supply-side of the market. The iterative process reflects the search for the new equilibrium. This implies that at the same time an economic foundation for the RAS method is given; it describes how disequilibria on the labour market are closed without adjusting the wage structure.

Another way to endogenize the coefficients in the production function is explaining these coefficients with the aid of some exogenous variables. As mentioned above, Den Hartog and Thoolen (1971), chose this approach, because the available data were not sufficient to solve this problem in a theoretically better founded way. They developed a distribution model in which an equation of the following form is estimated:

$$
\frac{e_{i q}}{e_{j q}}=\prod_{b=1}^{n} x_{b}^{\left(\eta_{i b}-\eta_{j b}\right)}
$$

where $e_{i q}$ is the share of employment with educational level $i$ in total employment in sector $q, x_{b}$ is the explanatory variable $\mathrm{b}$ and $\eta_{\mathrm{ib}}$ is the elasticity of the share of the demand for level $\mathrm{i}$ with regard to variable b. This function is linear in the logarithms and can therefore be estimated by linear regression.

Den Hartog and Thoolen select the following variables to explain the labour demand by sector and by educational level (the variables $x_{k}$ ):

1. the (desired) overall level of labour productivity or, in other words, the capital intensity (substitution between labour and capital is possible because the production function is of the Cobb-Douglas type);

2. the size of the sector, which indicates the possibilities of specific vocational training (the greater the sector, the more resources are available for an internal training system and the lower the external educational requirements);

3. the average number of workers per firm within the sector, which is an indication for the span of control (a high span of control requires a high level of education);

Unfortunately, the explanatory variables used by Den Hartog and Thoolen represent demand factors only. The supply side is modelled separately. ROA, for example, tries to incorporate 
supply effects in the demand model. ${ }^{27}$ Unlike Den Hartog and Thoolen, ROA uses a two-step analysis. First, the occupational structure is estimated. Subsequently, the educational structure is determined from the occupational structure. ${ }^{28}$

Dekker et al. (1990) describe the model used to determine the occupational structure of labour demand by sector. They suggest the following factors to have a significant influence on the occupational structure:

1. technological developments;

2. sector-specific cyclical effects;

3. sector-specific structural factors.

The following explanatory variables are chosen to give concrete form to these factors:

1. a trend variable, measuring the structural development of the size of the firms and other (macro-economic) variables;

2. recent investments divided by value added, indicating technological progress;

3. proportion of automation experts in total employment in a sector, which is suggested to be an indicator for the degree of automation of production;

4. the degree of capacity utilization, which measures sector-specific cyclical effects. ${ }^{29}$

It is suggested that the wage level could serve as an indicator for supply effects (Freeman's approach). However, the wage level is not incorporated into the model for three reasons: (1) lack of adequate data, (2) the fact that the wage level influences demand and supply, which implies that incorporating the wage structure would have made the model too complex and (3), and most important, the assumption that supply effects merely occur on the educational level, whereas the occupational structure of employment is assumed to be entirely dependent on demand factors. This implies that in the first step supply effects are not taken into account.

Beekman et al. (1991) describe the model used to make the second step, that is, the translation of the occupational structure into the educational structure of employment. Two steps are distinguished to obtain this translation. First, the structure by educational level is determined. Three factors are supposed to explain this structure:

1. technological developments;

2. supply factors;

3. a structural factor.

The following explanatory variables, which are used also by Dekker et al. (1990), are chosen to give concrete form to the technological factor:

1. the investment-value added ratio;

2. proportion of automation experts.

The supply factors are represented by:

27. However, ROA is not unique. For example, a comparable approach is chosen by CPB (1987).

28. ROA distinquishes two labour demand categories: replacement demand and expansion demand. The models described here are used to forecast the expansion demand (see Heijke and De Grip, 1991).

29. Like Den Hartog and Thoolen log-linear specifications are chosen. 
3. the relative share of a educational level in the potential labour force, as a proxy of substitution or crowding out processes (displacement) on the labour market; the educational structure of labour supply more or less determines the structure of labour demand. ${ }^{30}$

Finally, a fourth variable is included:

4. an occupational dummy, which is needed to cope with the fact that the occupationaleducational relationships also hold a fixed component.

In the second step the shares of each discipline within a level is determined. Because it is not clear which factors play a role here. Along with a trend variable, a sectoral and an occupational dummy are used.

To summarize it briefly, this section has paid attention to four ways to incorporate substitution possibilities and supply effects into the manpower requirements framework: (1) changing the production function, (2) using the wage level as a explanatory variable for the demand for and supply of labour, (3) using the RAS method and (4) using an explanatory variable which represents supply in the demand function. Section 4.3 deals with a fifth way: synthesizing the manpower requirements approach and the rate of return approach.

\subsection{Synthetic models}

Before attention is paid to some synthetic approaches, it has to be clear what is meant by a 'synthesis' between the manpower requirements approach and the rate of return approach. The distinction between incorporating substitution possibilities and supply effects into the manpower requirements framework on the one hand and synthesizing the manpower requirements approach and the rate of return approach on the other is not unambiguous. Several options can be distinguished. For example, every attempt to incorporate substitution possibilities or supply effects could be called a synthesis. ${ }^{31}$ This is a very broad definition. Here a smaller one is used. A model in which both requirements and rate of returns are calculated explicitly, is called a synthetic model.

Although no explicit model is elaborated, Blaug (1967) can be considered to be a synthetic approach. Blaug's statements have been described in section 1. To put it briefly, he states that the manpower requirements approach and the rate of return approach are both useful. It depends on the specific market features which approach is preferred. In a rigid labour market, the manpower requirements approach is useful. In a flexible market, the rate of return approach is more valuable.

Adelman's (1966) dynamic linear programming model is the first attempt to bring about a

30. In this case it would also be useful to incorporate a wage variable. It is, however, left out for the same reasons as mentioned above.

31. For example, the title of Freeman (1977) indicates that Freeman uses this definition. 
methodological synthesis between the two approaches. The fact that it is a linear programming model implies that an objective is optimized subject to a set of constraints. The objective is the maximization of GNP (or a variant of it). ${ }^{32}$ Because the model describes the entire economy, economic, technological and socio-cultural constraints are formulated for both the educational sector and the productive sectors.

In the educational sector the most important constraints are: the initial supply of teachers, the supply of school-buildings and the school-age population. Furthermore educational 'production functions', which describe how new students are 'transformed' into graduates, are formulated. In de productive sectors, especially the so-called labour supply inequalities are important within the scope of this paper:

$$
\sum_{j=1}^{J} l_{j k}, Y_{j}+\sum_{j=1}^{J} l_{j k}^{\prime} I_{j} \leq L_{k} \quad \text { for all } k
$$

where $Y_{j}$ is the output of the jth commodity, $I_{j}$ is total investment in the productive capacity of the $j$ th sector, $L_{k}$ is the labour supply of type $k$ and $I_{j k}$ and $I_{j k}$ are labour input coefficients. This equation shows that a fixed coefficient production function is used. ${ }^{33}$ Adelman distinguishes only three types of labour: workers, managers and employers. Between these types no substitution is possible, but within these types she assumes that there are non-zero substitution elasticities between labour with different levels of education.

With regard to the educational sector, both the optimal amount of graduates and their allocation over the economy are determined for every year of the planning period. As mentioned above, the objective for the economy as a whole is the maximization of GNP. This objective determines the required occupational structure. Because of the substitution possibilities within the three occupational clusters, the education plan is not determined yet. The optimal educational plan is characterised by the condition that the marginal gains of investments in a type of education are equal for all types. These marginal gains depend on the marginal benefits and the marginal costs. The marginal benefits are given by the shadow prices of the various education programs; the marginal costs are given by the shadow prices of an extra student, teacher or schoolbuilding.

Adelman's model is a synthesis between the manpower requirements approach and the rate of return approach. Two major characteristics of the model are similar to the manpower requirements models. First, although the production level and the requirements are calculated

32. Three alternatives are given:

1. maximization of the discounted sum of GNP;

2. maximization of the change og GNP;

3. minimization of the discounted sum of net foreign capital inflows.

33. See for more details about the constraints in the educational and the productive sectors Adelman (1966), pp. 390-403. 
simultaneously, equation (9) shows that the production level still determines the occupational structure. Equation (9) shows in the second place that the production technology is characterised by a Leontief production function. Because of the substitution possibilities within the three occupation categories, there is room for a rate of return element It can be found in the determination of the optimal educational plan; the marginal costs and benefits of investing in the various types of schooling are weight against each other.

Psacharopoulos (1979) states that there are serious problems with highly aggregated dynamic linear programming models, such as Adelman's. These problems are: the lack of adequate data, the unrealistic specification (linearity), the sensitivity of the results with regard to coefficients in the model and the need for terminal conditions to avoid unrealistic outcomes. ${ }^{34}$ Consequently the results are less reliable. Therefore, he elaborated a static linear programming model. The general structure of the model is as follows. Several labour skills are needed to generate output. The question is what is the most efficient skill structure to generate the production goal in the target year? Because the skill structure of the labour supply in the base year is given, this question can be reformulated in, what is the most efficient educational investment plan? Two criteria are used to determine the efficiency of a plan: (1) a profitability criterion (a rate of a return element) and (2) a technological criterion (a manpower requirements element within a substitution range).

Psacharopoulos suggests an iterative approach. This approach consists of two steps in which the synthetic character of the model becomes clear. The first step deals with calculating the ex post rate of returns of educational investments in every labour skill done in the past. Differences between these rate of returns indicate the inefficiency of the educational plan. Resources should be reallocated in order to increase the investments in the skills which yield the highest returns.

In the second step the information of the first step is used to evaluate educational plans for the future. However, this information is not sufficient to take an adequate decision, because it does not make clear which skill structure is needed from a technological point of view. To add this kind of information, a manpower requirements model can be used. A plan which is laid based on this technological information can be evaluated with regard to the profitability criterion.

The second step implies that in an iterative process, the manpower requirements model and the rate of return approach can be used in turn to obtain the optimal plan which satisfies both the profitability and the technical criterion.

This section has shown that during the last twenty years the emphasis was laid heavily on incorporating substitution possibilities and supply effects into the manpower requirements framework. In the final section some conclusive remarks will be made about the past, the current 'state of the art' and the future.

34. For further details, see Psacharopoulos (1979), p. 292. 


\section{CONCLUSIONS}

The aim of this paper was to give an overview of some important aspects of manpower planning in general and the manpower requirements approach in particular. Attention has been paid to the background and the methodology of the manpower requirements approach.

The manpower requirements approach uses a fixed coefficient production function to forecast the occupational and educational structure of labour demand. These forecasts are compared with supply forecasts to calculate the expected gaps on the heterogenous labour market. These gaps indicate the adjustments which are needed in the educational system.

In the 1960s, the economies changed rapidly and the educational system became more and more important. Therefore, educational planning in general and the manpower requirements approach, which was developed in the 1950s, in particular were very popular during this period. The OECD played a pioneering role by using the approach in the Mediterranean Regional Project. The OECD decided to use the manpower requirements approach, because it was in alignment with both the ideas about planning and the view on the labour market in those days.

The popularity of the manpower requirements approach decreased quickly at the end of the 1960s. The critics gained the upper hand. Their arguments can be subdivided into two parts: fundamental and methodological arguments. The fundamental criticism stresses in particular the weakness of the techniques and the doubts about the usefulness of the approach for planning purposes, because the forecasts may have no impact. Besides the remarks about the data and the character of the results, the methodological criticism is concerned especially with the assumptions made. The implication of the use of a fixed coefficient production function attracted by far the most attention here: that is, the lack of substitution possibilities and supply effects.

The advocates of the approach have replied to these remarks in four ways. First, they tried to refute the criticism (for example Freeman, 1977, 1980). Secondly, they have changed the aim of making manpower forecasts. Instead of a planning instrument, the manpower planning framework is often used now as an instrument generating information for all participants on the labour market. This can be considered as a reply to the fundamental criticism. In the third place, they shortened the time horizon of their forecasts. Finally, they have searched for improvements of the methodology, in particular by trying to incorporate substitution possibilities and supply effects. This can be considered as a reply to the methodological criticism.

The relevance of manpower planning has swollen as a result of the use of manpower forecasts in an information system of the labour market. Borghans (1993) shows that the provision of good labour market forecasts improves both the labour market performance and the fit between the educational system and the labour market. However, the relevance of making manpower forecasts can be increased even more if the quality of the forecasts is improved. Shift and share analyses for the Netherlands (for example Peeters (1990) and NEI (1986)) have shown that 
$-32-$

shifts in the educational structure are due to shifts in the occupational structure of labour demand as well as shifts in the educational structure within occupations. These shifts have to be explained, in order to improve the labour market information.

This does not imply, however, that the manpower requirements approach is no longer in the picture. Rigidities still set bounds to a perfect matching between demand and supply on the labour market. Recent developments in economic labour market theory are concerned with the adjustments processes that occur in such a rigid market. A better foundation of the manpower requirements models on these labour market theory developments may be of great value to explain the shifts mentioned above. 


\section{REFERENCES}

Adelman I. (1966), 'A Linear Programming Model of Educational Planning: A Case Study of Argentina, in: Adelman I. and Thorbecke E., The Theory and Design of Economic Development, The Johns Hopkins Press, Baltimore.

Ahamad B. and Blaug M. (1973), The Practice of Manpower Forecasting; a Collection of Case Studies, Elsevier, Amsterdam.

Beekman T.B.J., Dekker, R.J.P., De Grip A. and Heijke J.A.M. (1991), 'An Explanation of the Educational Structure of Occupations', Labour, vol. 5, nr. 3, pp. 151-163;

Blaug M. (1967), 'Approaches to Educational Planning', The Economic Journal, vol. 76, june, pp. 262-287.

Borghans L. (1993), Educational Choice and Labour Market Information, Thesis, Maastricht (forthcoming).

Cohen S.I. (1988), 'Manpower Planning Models with Labour Market Adjustment: Applications to Columbia, Republic of Korea and Pakistan', Economic Modelling, vol. 5, january, pp. 19-31.

Cohn E. and Geske T.G. (1990), The Economics of Education, Pergamon Press, Oxford, third edition.

CPB (1987), De arbeidsmarkt naar opleidingscategorie 1975-2000, CPB-werkdocument nr. 17, Den Haag.

Dekker R.J.P., De Grip A. and Heijke J.A.M. (1990), 'An Explanation of the Occupational Structure of Sectors of Industry', Labour, vol. 4, nr. 3, pp. 3-31.

Den Hartog H. and Thoolen B.A. (1971), Requirements and Supply of Qualified Manpower; Projections for the Netherlands la Tentative Approach), Central Planning Bureau Occasional Papers nr. 2, CPB, Den Haag.

Evans G.J. and Lindley R.M. (1973), 'The Use of RAS and Related Models in Manpower Forecasting', Economics of Planning, vol. 13, nr. 1-2, pp. 53-73.

Freeman R.B. (1977), 'Manpower Requirements and Substitution Analysis of Labor Skills: a Synthesis', in: Ehrenberg R.G. (ed), Research in Labor Economics: an Annual Compilation of Research, JAI Press, Connecticut.

Freeman R.B. (1980), 'An Empirical Analysis of the Fixed Coefficient 'Manpower Requirements' Model, 1960 - 1970', Journal of Human Resources, vol. 15, nr. 2, pp. 176-199. 
Heijke J.A.M. and De Grip A. (1991), The Information System on Education and the Labour Market Developed by ROA, ROA-W-1991/2E, Maastricht.

Hollister R. (1967), A Technical Evaluation of the First Stage of the Mediterranean Regional Project, OECD, Paris.

Hughes G. (1991), Manpower Forecasting. A Review of Methods \& Practice in Some OECD Countries, The Economic and Social Research Institute, Dublin.

NEI (1986), Een Verkenning van de Arbeidsmarkt naar Beroep en Opleiding tot 1990, OSAwerkdocument nr. 17, Zoetermeer.

OECD (1965), The Mediterranean Regional Project: an Experiment in Planning by Six Countries, Paris.

OECD (1971), 'Critical Evaluation of the Current Methodology of Manpower Forecasting in West European Countries', in: United Nations, Investment in Human Resources and Manpower Planning, New York.

Parnes H.S. (1962), Forecasting Educational Needs for Economic and Social Development, OECD, Paris.

Peeters H.M.M. (1990), An Explanation of the Occupational and Educational Structure of Employment by means of Multinomial Logit, ROA-W-1990/4E, Maastricht.

Psacharopoulos G. (1973), 'Substitution Assumptions Versus Empirical Evidence in Manpower Planning', De Economist, vol. 121, nr. 6, pp. 609-625.

Psacharopoulos G. (1979), 'Synthetic Approaches in Manpower Planning', De Economist, vol. 127, nr. 2, pp. 287-297.

Psacharopoulos G. (1987a), 'The Manpower Requirements Approach', in: Economics of Education: Research and Studies, Pargamon Press, Oxford.

Psacharopoulos G. (1987b), 'The Tinbergen Model', in: Economics of Education: Research and Studies, Pargamon Press, Oxford.

Ritzen J.J.M. (ed) (1985), Menselijk Kapitaal en Conjunctuur: een Voorstudie, Erasmus University, Rotterdam.

Tinbergen J. (1963), 'Employment Forecasting and Planning', in: OECD, Employment Forecasting, Paris. 
$-35-$

Tinbergen J. and Bos H.C. (1965), 'A Planning Model for the Educational Requirements of Economic Development', in: OECD, The Residual Factor and Economic Growth, Paris.

Van Hoof J.J. and Dronkers J. (1980), Onderwijs en Arbeidsmarkt, Van Loghum Slaterus, Deventer. 